\title{
Reactions of Surface Amines with Heterobifunctional Crosslinkers Bearing both Succinimidyl Ester and Maleimide for Grafting Biomolecules
}

\author{
Shou-Jun Xiao ${ }^{1,2} *$, Samuel Brunner ${ }^{3}$, Marco Wieland $^{1+}$ \\ contribution from ${ }^{1}$ Laboratory for Surface Science and Technology, Department of \\ Materials, Swiss Federal Institute of Technology, CH-8092, Zürich, Switzerland, \\ State Key Laboratory of Coordination Chemistry, Nanjing University, Nanjing \\ 210093, China , ${ }^{3}$ Swiss Federal Laboratories for Materials Testing and Research, \\ Überlandstrasse 129, CH-8600 Dübendorf, Switzerland
}




\section{S-Chart 1 Crosslinkers}

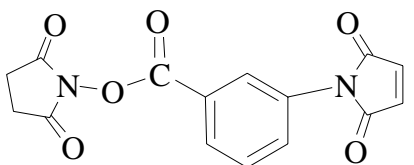

a N-Succinimidyl-3-maleimidylbenzoate

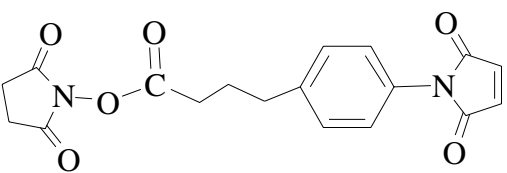

b N-Succinimidyl-4-(4-maleimidylphenyl)-butyrate

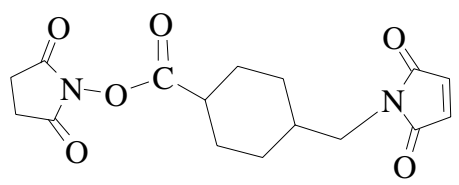

c $\mathrm{N}-$ Succinimidyl trans-4-(maleimidylmethyl) cyclohexane-1-carboxylate

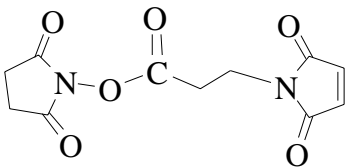

d N-Succinimidyl-3-maleimidylpropionate<smiles>O=C(CCCN1C(=O)C=CC1=O)ON1C(=O)CCC1=O</smiles>

e $\mathrm{N}$-Succinimidyl-4-maleimidylbutyrate

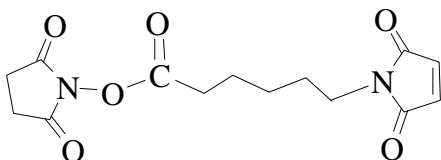

f N-Succinimidyl-6-maleimidylhexanoate

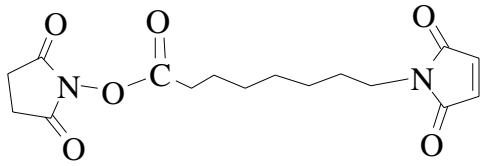

g N-Succinimidyl-8-maleimidyloctanoate

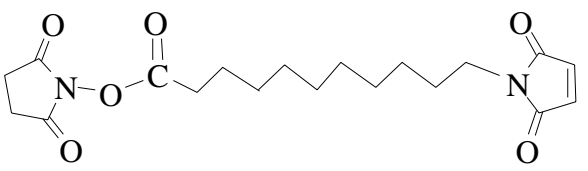

h N-Succinimidyl-11-maleimidylundecanoate 

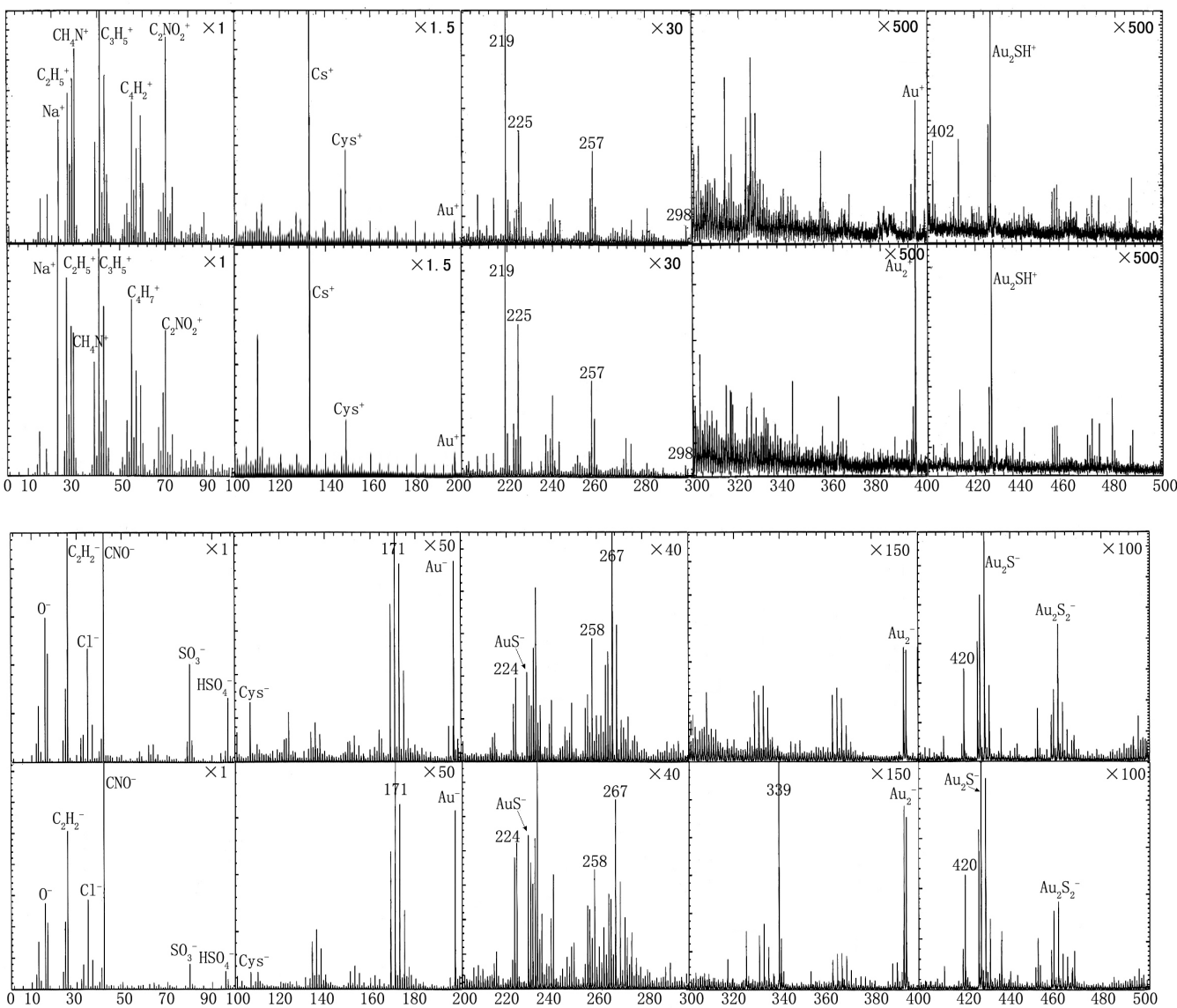

S-Figure 1. TOF-SIMS negative and positive spectra of $\mathbf{3 f}$ (upper) and $\mathbf{3 m}$ (bottom). 